\title{
The mature anther-preferentially expressed genes are associated with pollen fertility, pollen germination and anther dehiscence in rice
}

\author{
Sheng Ling ${ }^{1}$, Caisheng Chen ${ }^{1}$, Yang Wang ${ }^{1}$, Xiaocong Sun ${ }^{1}$, Zhanhua $\mathrm{Lu}^{2}$, Yidan Ouyang ${ }^{3}$ and Jialing Yao ${ }^{1 *}$
}

\begin{abstract}
Background: The anthers and pollen grains are critical for male fertility and hybrid rice breeding. The development of rice mature anther and pollen consists of multiple continuous stages. However, molecular mechanisms regulating mature anther development were poorly understood.

Results: In this study, we have identified 291 mature anther-preferentially expressed genes (OSSTA) in rice based on Affymetrix microarray data. Gene Ontology (GO) analysis indicated that OsSTA genes mainly participated in metabolic and cellular processes that are likely important for rice anther and pollen development. The expression patterns of OsSTA genes were validated using real-time PCR and mRNA in situ hybridizations. Cis-element identification showed that most of the OsSTA genes had the cis-elements responsive to phytohormone regulation. Co-expression analysis of OsSTA genes showed that genes annotated with pectinesterase and calcium ion binding activities were rich in the network, suggesting that OsSTA genes could be involved in pollen germination and anther dehiscence. Furthermore, OsSTA RNAi transgenic lines showed male-sterility and pollen germination defects.
\end{abstract}

Conclusions: The results suggested that OsSTA genes function in rice male fertility, pollen germination and anther dehiscence and established molecular regulating networks that lay the foundation for further functional studies.

Keywords: Mature anther, Microarray, Rice, RNA interference

\section{Background}

Rice is a staple food for nearly half of the world's population and a model species for monocot developmental studies [1]. Stamen is the male reproductive organ that consists of anthers and filaments. Anthers produced pollens, the male gametes, which are one of the major routes of gene flow in nature through cross-pollination [2]. In addition, anther development and pollen fertility are directly associated with rice yield in the agricultural production. The key role of male sterility in rice heterosis spurred people to investigate the regulatory mechanism of pollen development [3]. Therefore, rice anther and pollen development is an active area of research plant reproduction and crop breeding. Anther development in rice was divided into 14 stages, which was consistent with that of Arabidopsis [2,4]. To summarize, anther

\footnotetext{
* Correspondence: yaojlmy@mail.hzau.edu.cn

${ }^{1}$ College of Life Science and Technology, Huazhong Agricultural University,

Wuhan 430070, China

Full list of author information is available at the end of the article
}

development initiates with stamen primordium formation, followed by the primordium differentiation to form the anther wall and pollen mother cells. Subsequently, the meiocytes undergo meiotic divisions and the anther wall degenerates. Afterward, the released microspores undergo two rounds of mitosis to develop into tri-cellular pollen and the pollen grains further accumulate starch and lipidic materials. Last, the pollen grains are released from anthers during the anther dehiscence.

Genome-wide expression analysis during rice anther development could help establish regulatory networks, and further analysis that investigates co-expressed gene groups may help identify DNA cis-elements and their interacting protein factors. In recent years, several transcriptome analyses of rice male reproductive organs were reported [5-8]. These transcriptomic studies using high density microarrays revealed the complexity of gene expression during anther development. The studies based on Agilent $44 \mathrm{~K}$ microarray or Affymetrix rice genome array showed that most rice genes were 
expressed in developing anthers and the expression of thousands of genes were anther-specific [5,7]. Furthermore, some reports utilized laser-microdissection to isolate microspores and the tapetum layer of developing anthers [6]. More recently, transcriptome profilings revealed genes contributing to specific aspects to meiosis and male gametophyte development [8]. Nevertheless, transcriptomic analyses of genes predominantly expressed in mature anthers instead of developing anthers were not performed.

During anther and pollen maturation, pollen metabolism, anther dehiscence, and pollen germination after pollination were key events for male fertility. Previous studies described several genes that function in anther dehiscence and pollen tube growth. The SIZ1 gene in rice encoded a SUMO E3 ligase and was expressed in all tissues. The spikelet sterility in siz1 mutant and SIZ1-RNAi lines was caused by defective anther dehiscence but not defective pollen [9]. Spikelet sterility in rice pss1 mutants was due to a failure in anther dehiscence at the time of spikelet opening or even after its closing [10]. However, little is known about the genetic control of anther dehiscence in rice and how it is coordinated with other developmental processes in the anther and florets.

Several studies have revealed genes that played roles in the pollen tube growth such as OsAP65, VGD1, Pi CDPK and MGP2 [11-14]. The OsAP65 encoded a transmembrane protein and was expressed in various organs, and the anthers of OsAP65 mutant developed normally until mature stage, showing defect in pollen tube elongation. VGD1 was expressed specifically in pollen grains and pollen tube in Arabidopsis and encoded a pectin methylesterase (PME)-homologous protein that acted in cell wall modification. vgd1 pollen tubes were unstable and burst more frequently than those of wild type. In addition, two pollen-expressed calmodulin-like domain protein kinases $P i C D P K 1$ and $P i C D P K 2$ in Petunia, and MALE GAMETOPHYTE DEFECTIVE 2 (MGP2) in Arabidopsis were involved in pollen germination and pollen tube growth. These results showed that the genes expressed in pollen were necessary for pollen grain germinate or pollen tube elongation. Although gene knockdown or knockout approaches can be used to identify gene functions, they do not illustrate the systems level molecular networks of mature anther development. The molecular mechanism concerning this specific late stage anther development was still poorly understood compared with early- or mid-term stages of the anther development.

In this study, we aimed to provide molecular insights into genes preferentially expressed in rice mature anthers by establishing their regulatory networks based on transcriptome profiling and gene co-expression analysis. Genes highly expressed in the mature stamen at higher than 4 fold levels compared with other organs in Minghui63 (MH63) or Zhenshan97 (ZS97) rice were defined as mature anther-preferentially expressed genes (OsSTA) [15]. Expression patterns during anther development and co-expression analyses were performed to discover the potential functions of the OsSTA genes. We have validated the microarrays data by quantitative real-time PCR. In addition, some genes were chosen to confirm the spatial and temporal expression by in situ hybridization. Finally, we have constructed OsSTA-RNAi transgenic plants for gene functional characterization.

\section{Results}

\section{Identification and nomenclature of OSSTA genes}

The definition of mature anther in this experiment was that with tri-nucleus and materials accumulation of pollens, followed with the anther connective burst. The data for rice mature anther-preferentially expressed genes was cited from the results of tissue-specific expressed genes in previous study, which contain 21 tissues during the rice development [15]. Based on the data, we have identified 402 probe sets preferentially expressed in the mature anther and 4 folds higher than other tissues. During them, 83 probe sets were removed for absence of the gene IDs. The remaining 319 probe sets corresponding to 291 genes were considered as mature antherpreferentially expressed genes and were named from OsSTA1 to OsSTA291 according to their positions on pseudomolecules (Figure 1). The microarrays concerning the rice entire life cycle in Wang et al. 2010 [15] were used for hierarchical clustering analysis. The GSE19024 Affymetrix microarray from NCBI showed that all of the 291 genes had high transcript accumulations in mature anther. A hierarchical cluster displaying the $\log 2$ of average signal values for the 291 OsSTA genes was generated in MH63 (Figure 2; Additional file 1: Table S1a; Additional file 2: Table S2). The cluster suggested that all genes showed the highest expression signals in mature anther. Another microarray GSE13988 was used to confirm the expression patterns of the 291 OsSTA genes, which contained 8 anther developmental stages from hypodermal archesporial cells formation to tri-cellular pollen stage in Nipponbare (Fujita et al. 2010 [7]). The hierarchical clustering analysis based on this array data was carried out, using the same probe sets in MH63 (Figure 3; Additional file 1: Table S1b). The heat map showed that $85 \%$ (247/ 291) of the OsSTA genes had the highest expression levels in the anther with tri-cellular pollen. Besides, most of them had expression signals in bi-cellular pollens. Therefore, we defined the 291 OsSTA genes as rice mature anther-preferentially expressed genes and performed further analysis on these OsSTA genes. Detailed information on the OsSTA genes such as accession numbers, protein properties, and isoelectric points is listed in Additional file 


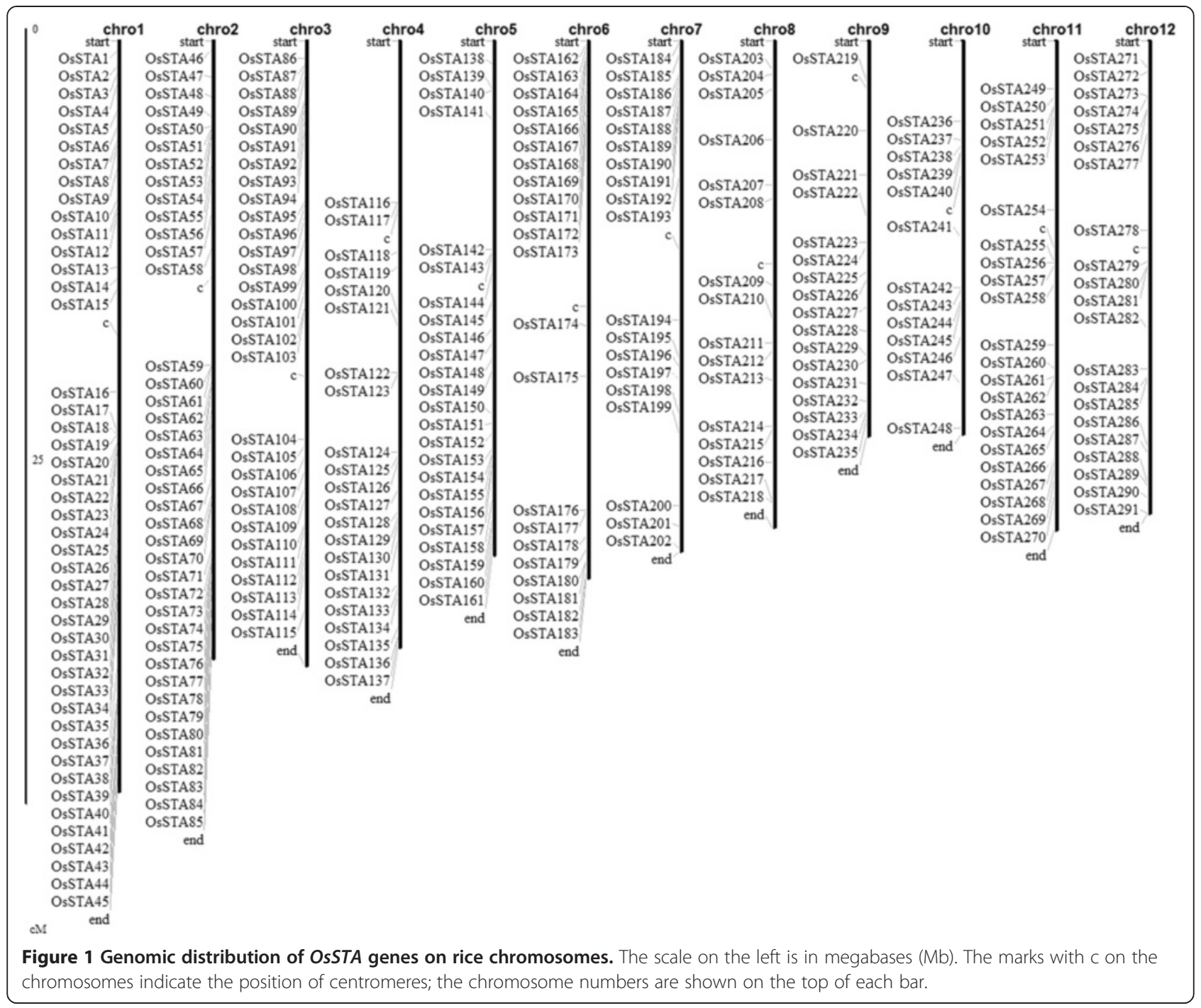

3: Table S3, at the times we take the OsSTA genes sequence information in Additional file 3: files 1-3.

\section{Validation of the microarrays data by quantitative real-time reverse transcription-PCR}

Sixteen OSSTA genes were randomly chosen for further validation by real-time PCR (primers details see Additional file 4: Table S4a). Various rice tissues from Zhonghua11 (ZH11) were used, includes flowering stage roots, stems and flag leaves, the panicles from archesporial cells formation to bi-cellular pollen stage (P3-P8), paleas (contains pistils), lemmas and mature anthers in tri-cellular mature pollen stage [16]. In this experiment, the ubiquitin was used for internal control gene. The results of real-time PCR showed that the expression patterns of these genes were in general agreement with the data of the microarrays (Figure 4). Remarkably, the expression level was higher in the mature anther than those in the other tissues (at least 4 fold). OsSTA46 (OsO2g01990), OsSTA50
(Os02g09530), OsSTA58 (Os02g20530) and OsSTA208 ( Os08g15090) showed 4 to 10 fold, OsSTA5 (Os01g08340), OsSTA28 (Os01g50470), OsSTA68 (Os02g43840), OsSTA99 (Os03g23030), OsSTA132 (Os04g52950), OsSTA150 (Os05g37150), OsSTA201 (Os07g47120), OsSTA220 (Os09g09630) and OsSTA263 (Os11g36740) showed 10 to 100 fold, and OsSTA24 showed more than 200 fold than other tissues. The results confirmed that these genes were mature anther-preferentially expressed genes. Furthermore, OsSTA168 (Os06g05710) and OsSTA196 (Os07g31830) showed more than one thousand fold than other tissues, which indicated these two genes specifically expressed in the mature anther and had no signal in other tissues.

The spatial and temporal activities of OsSTA genes in rice anther

In situ hybridization was performed to examine the temporal and spatial expression patterns of OsSTA genes in 


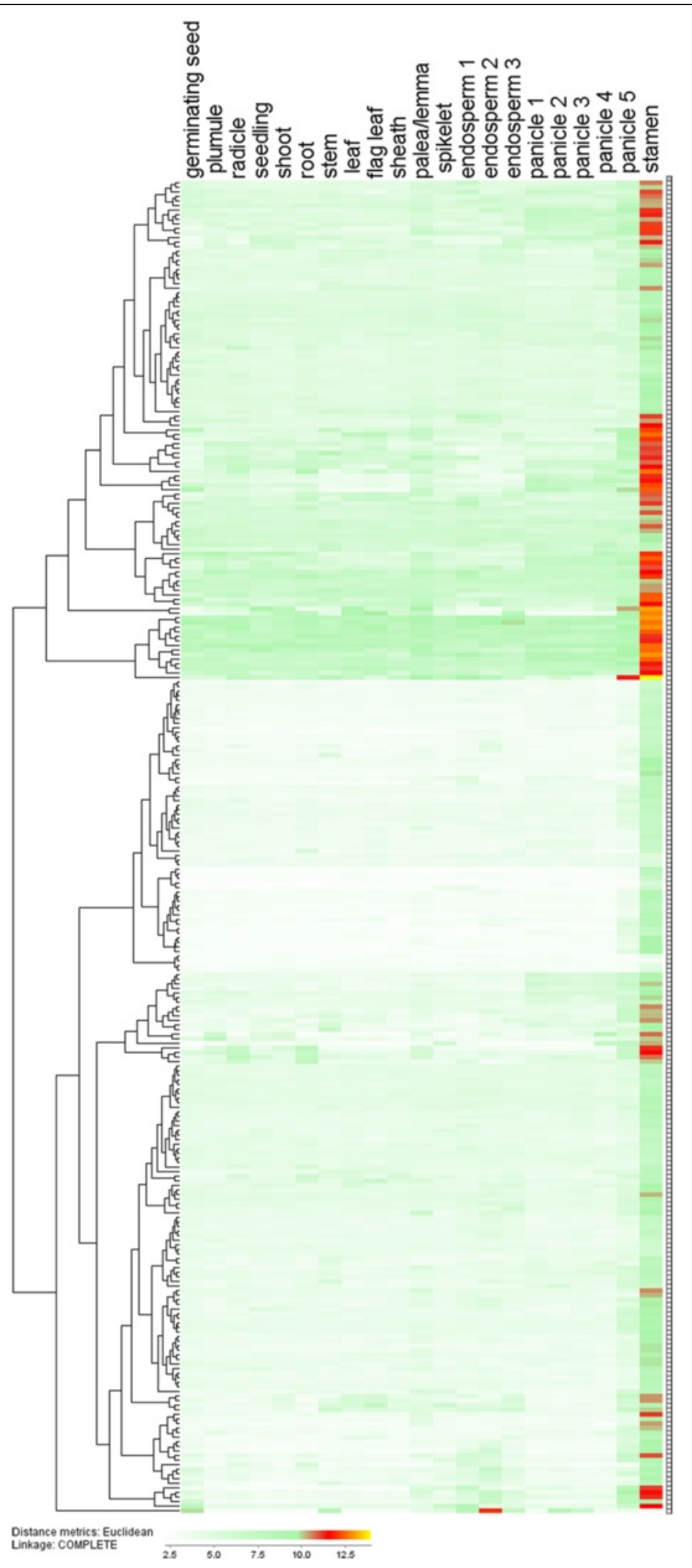

Figure 2 A hierarchical clustering of 291 OSSTA genes according to their expression patterns during rice life cycle in MH63. Color bar at the base represents $\log _{2}$ expression values: white, representing low expression; green, medium expression; red and orange, high expression. 


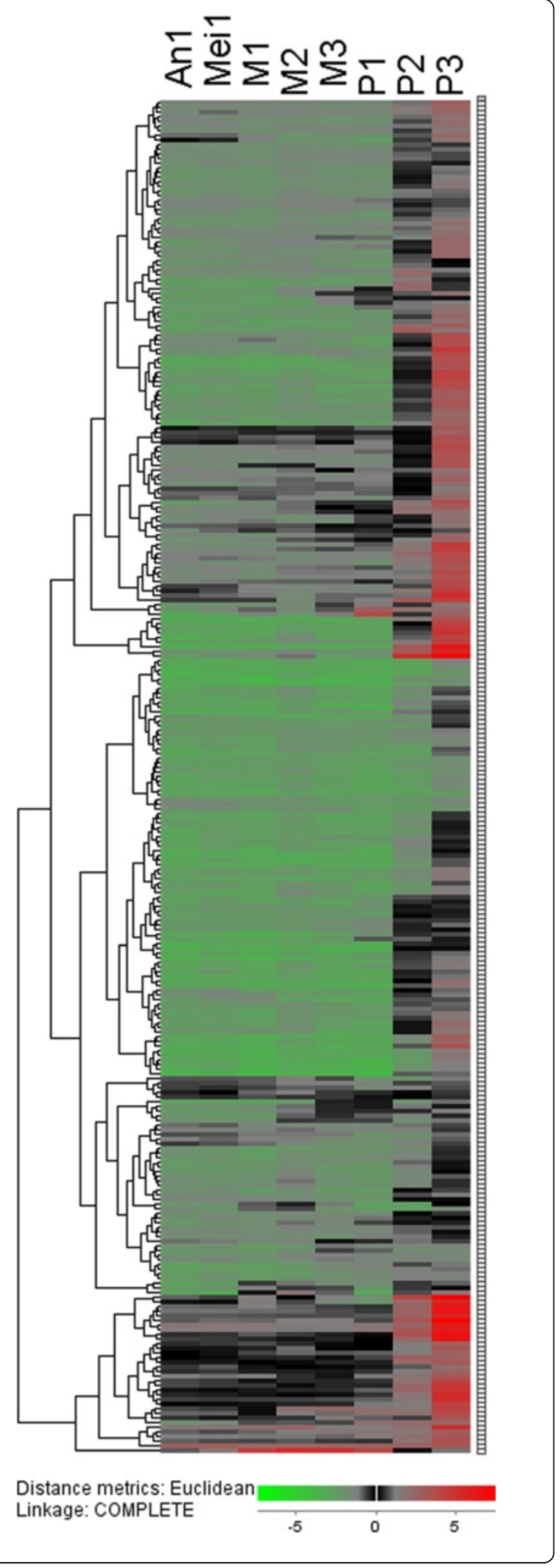

Figure 3 Expression patterns of OSSTA genes in rice male reproductive process. Color bar at the base represents log2 expression values: green, representing low expression; black, medium expression; red, high expression. An1: Anther in hypodermal archesporial cells forming stage; Mei1: Anther in pollen mother cells at pre-meiotic S/G2 stage; M1: Anther in pollen mother cells at meiotic leptotene stage; M2: Anther in pollen mother cells at meiotic zygotene-pachytene stage; M3: Anther in pollen mother cells at meiotic diplotene-tetrad stage; P1: Anther in uni-nucleated gametopyte stage; P2: Anther in bi-cellular gametopyte stage; P3: Anther in tri-cellular mature pollen stage.

rice anther. Five genes from real-time PCR test, including OsSTA28, OsSTA68, OsSTA99, OsSTA196, and OsSTA208, were selected for mRNA in situ hybridization. The transverse sections of roots, stems and flag leaves in flowering stage, anther from pollen mother cell stage to mature pollen stage were used for analysis (Figure 5). No signal was detected in the anthers of microspore stage using a dig oxigenin (DIG)-labeled OsSTA genes sense probe as a control.

The OsSTA genes showed similar spatial and temporal expression patterns, all of which had no detection signal in vegetative organs and early stage anthers such as pollen mother cell and meiosis stage using the DIG-labeled OsSTA genes anti-sense probe for research (Figure 5; Additional file 5: Figure S1). The genes expression signal in anther could be detected from microspore stage (except OsSTA28 and OsSTA68) to tri-cellular mature pollen stage, and the anther wall had the transcript accumulation. More accurately, OsSTA28 expressed in the pollens of mature anther and the anther wall from bi-cellular pollen to mature anther stage. The expression signal of OsSTA99, OsSTA196 and OsSTA208 appeared on the anther wall from microspore stage to mature anther stage, in addition, OsSTA99 had transcript accumulation in the mature pollens. Besides, the OsSTA68 was only expressed in anther wall from bi-cellular pollen stage to mature anther stage. Interestingly, all of the OSSTA genes had no expression signal in the stomium of anther. The similar expression patterns implied that the detective OsSTA genes might perform functions during the mature processes of the anther.

\section{Gene ontology (GO) analyses and functional classification}

AgriGO is a useful tool to analyze the GO annotations concentrating in molecular function, biological process and cellular component [17]. We thus analyzed the GO annotations of 291 OsSTA genes by the agriGO tools, which indicated functionality of 286 genes (Additional file 6: Table S5). These 286 genes were classified into 15 categories: cellular process, cellular component organization, regulation of biological process, biological regulation, metabolic process, establishment of localization and localization in biological process; macromolecular complex, cell part, cell and organelle in cellular component; transcription regulator activity, transporter activity, catalytic activity and 


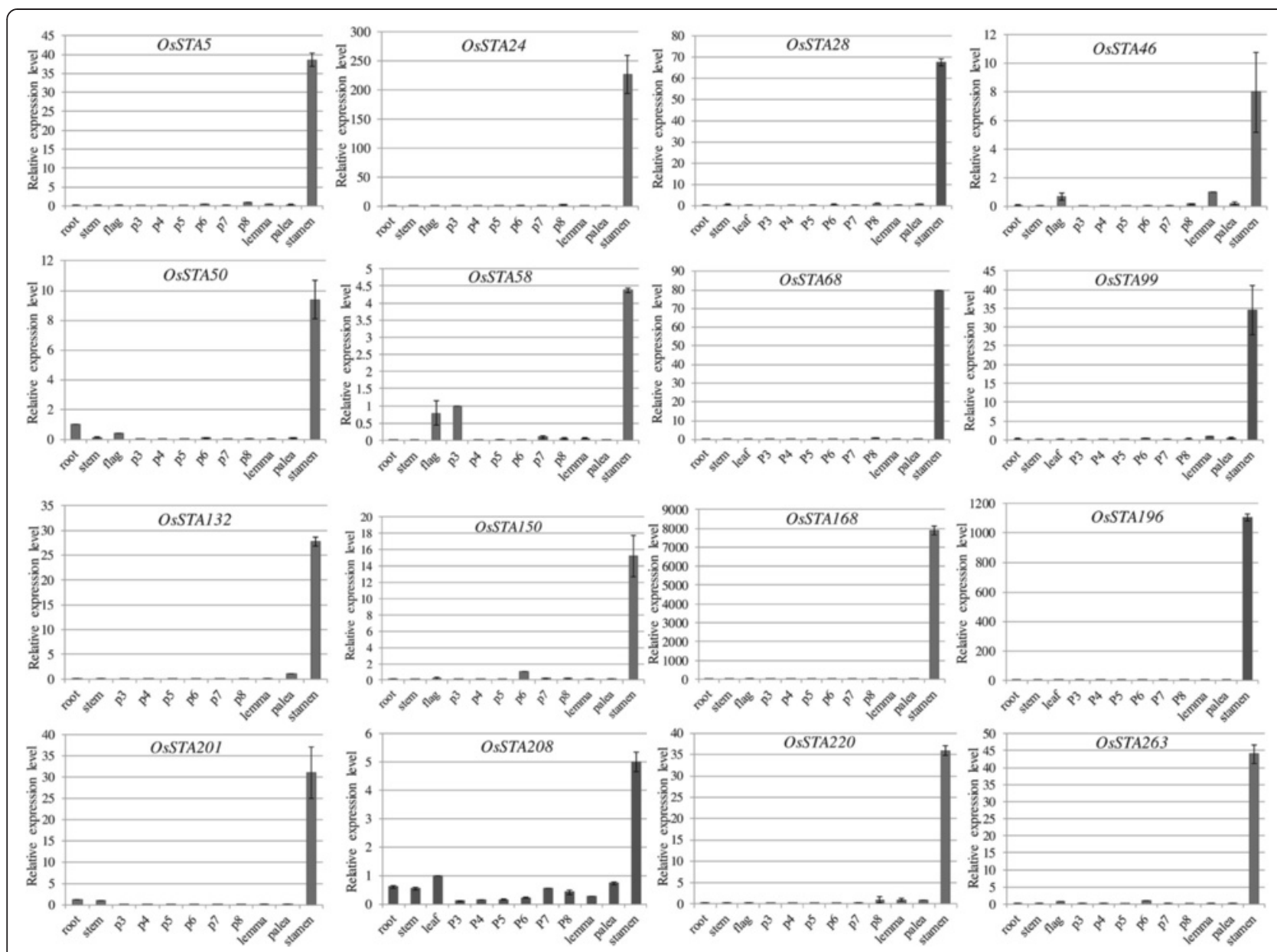

Figure 4 The relative expression level of selected 16 OsSTA genes in ZH11. Y-axis represents relative expression values obtained using real-time PCR. X-axis depicts developmental stages as explained.

binding activity in molecular function (Figure 6). During these GO annotations, the OsSTA genes enriched in categories of cellular process $(62 / 286)$, metabolic process (67/286), catalytic activity (70/286) and binding activity (80/286). More exactly, the 67 genes belong to metabolic process were mainly involved in cellular metabolic process, macromolecule metabolic process and primary metabolic process. The 70 genes encoding proteins with catalytic activity contained 16 kinases, 28 transferases and 30 hydrolases. Further analysis showed that most of the enzymes participated in the metabolic process, in the form of compounds. These results suggested that OsSTA genes might play crucial roles in cellular development and metabolic processes in rice mature anthers.

\section{Identifying mature anther highly expressed genes and GO analyses}

To search for genome-wide molecular mechanisms in rice mature anthers, we analyzed all the mature anther highly expressed genes. In Arabidopsis, rice and other organisms, co-expression analysis was used for identifying functional transcription regulators [18]. The distribution of the Pearson's correlation coefficients (PCC) suggested that the PCC higher than 0.75 was significant for two correlated genes [19]. The 42195 PCCs of each pair for the OsSTA genes were calculated, during them, 32470 PCCs were higher than 0.75 , which revealed that most OsSTA genes had similar expression pattern, therefore, we detected the co-expression genes of OsSTA genes to find the mature anther highly expressed genes (Additional file 7: Table S6a). Each of the OsSTAs was selected to identify the co-expressed genes using expression data from CREP database (http://crep.ncpgr.cn/crep-cgi/query_by_tree.cgi), and the PCCs greater than 0.8 were chosen for next step analysis by the removal of duplicated genes. Based on this, 1510 genes were found to be highlycorrelated with the expression of OsSTA genes group (Additional file 7: Table S6b).

The co-expression gene annotations were identified in the agriGO database (Additional file 7: Table S6c). Afterwards, the results involved in biological process, cellular component and molecular function were graphical 


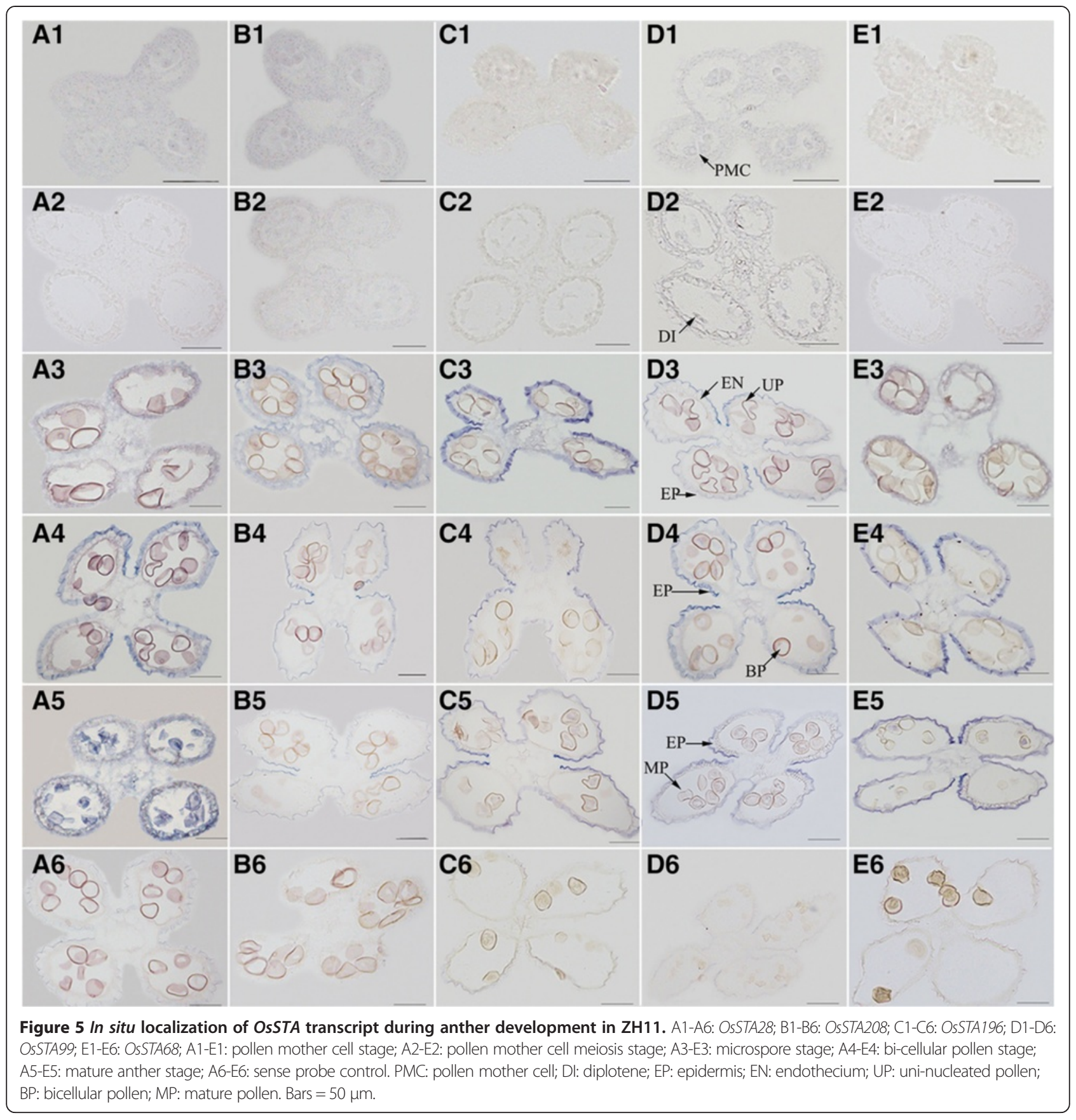

(Additional file 5: Figure S2). The enriched GO annotations particularly concentrated on metabolic process, localization process, cellular process, signal transduction, biological regulation and cell wall organization or biogenesis. They encoded proteins forming macromolecular complex in cell or extracellular. The molecular functions of these genes were transporter activity, enzyme regulator activity, catalytic activity and binding. These annotations were mainly consistent with OsSTA genes, except for signal transduction and enzyme regulator activity, which revealed that the genes highly expressed in mature anther might function together with OsSTA genes. Among these genes, 31 genes were annotated with pectinesterase activity (GO: 0030599), whereas only 103 genes had this activity in the rice genome. The graphical results of gene annotations were showed in Figure 7 . The graphs revealed that these genes encoded enzymes that function as modifiers of the cell wall. Also, 25 of these genes encoded proteins showing enzyme inhibitor activity and participated in enzyme regulator process. These results suggested that pectinesterase could be necessary for 


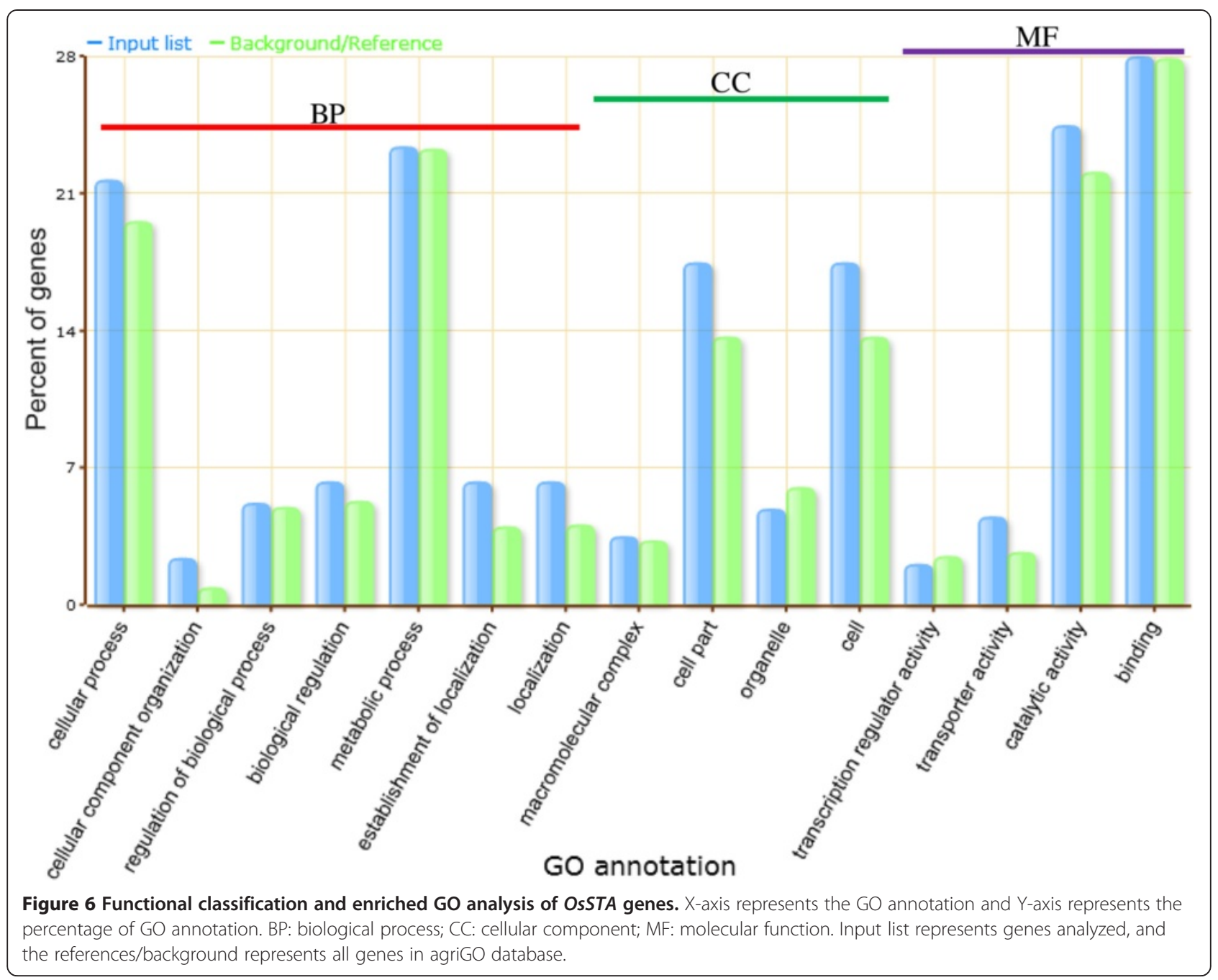

anther development in mature pollen. Moreover, 37 genes that code for proteins with the calcium ion binding (GO: 0005509) activities were identified, which were annotated with catalytic activity and participated in metabolic processes (Figure 8).

\section{Characterization of cis-elements in OsSTA gene promoters}

In rice, the levels of auxin, gibberellins, ethylene and jasmonic acid in mature anthers were higher than in other tissues [20]. To investigate whether the OsSTA genes participated in phytohormones regulatory networks, cis-elements for phytohormone responsiveness at the promoter regions of OsSTA were identified using the PLACE database (http://www.dna.affrc.go. jp/PLACE/index.html). Based on promoter analysis, 11 cis-elements for abscisic acid responsiveness, 6 ciselements for auxin responsiveness, 3 cis-elements for gibberellin response, 3 cis-elements for ethylene response, and 3 cis-elements for jasmonic acid response were used for phytohormone responsiveness research.
As a result, 251 genes had the cis-elements that respond to phytohormones, among which 209 genes had more than one phytohormone response cis-elements. It was interesting that 107 genes had abscisic acid response elements in their promoters, 138 gene promoters had auxin response cis-elements, 141 genes were predicted to respond to gibberellin, and 192 gene promoters had jasmonic acid responsive elements. However, no gene has cis-elements for ethylene and cytokinin (Additional file 8: Table S7). Therefore, the results revealed that most of the OsSTA genes may be regulated by the phytohormone abscisic acid, auxin, gibberellins and jasmonic acid in mature anthers. Additionally, individual OsSTA gene promoter analysis showed that OsSTA28 and OsSTA208 had the abscisic acid, auxin, and jasmonic acid responsive elements; OsSTA99 and OsSTA196 might respond to gibberellins and jasmonic acid; OsSTA68 possessed auxin, gibberellins and jasmonic acid responsive elements. 


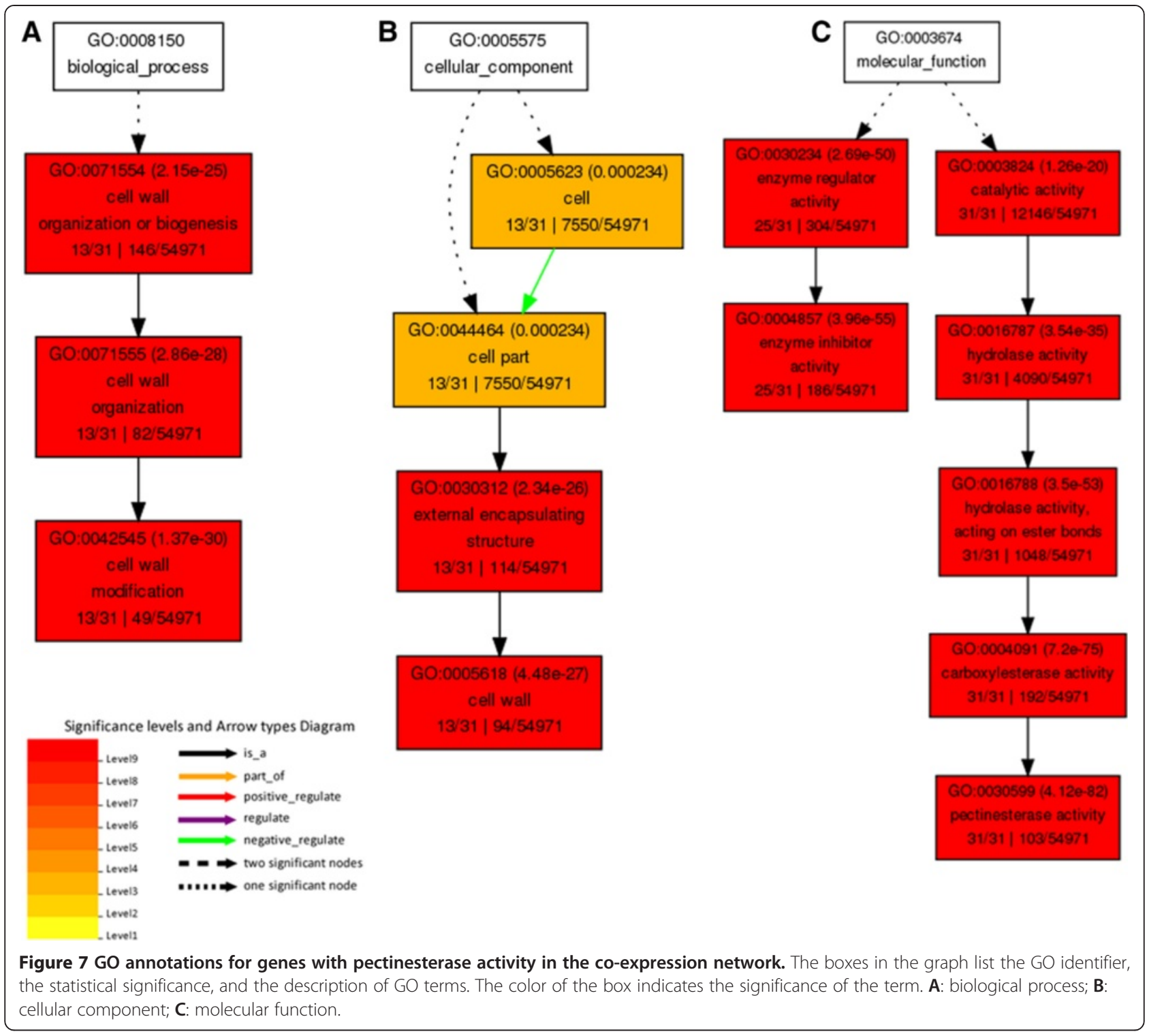

Reduced expression of OsSTA results in male sterility and defect of pollen germination in OSSTA RNAi transgenic plants

To study the functions of OsSTA genes in rice anthers, we employed methods of dsRNA-induced RNA interference according to published procedures [21-23]. Three genes (OsSTA28, OsSTA99 and OsSTA208) were selected for RNAi, and the gene-specific coding sequence was chose for gene-specific interference.

After transforming dsRNA into rice protoplasts, more than 30 regenerated transgenic plants per OsSTA gene were obtained. Among the $\mathrm{T}_{0}$ OsSTA-RNAi transgenic plants, the positive transgenic plants showed $11.3 \%$ to 85.6\% decreased expression level of OsSTA compared with the WT (Additional file 5: Figure S3). Three positive transgenic $\mathrm{T}_{0}$ lines of OsSTA genes (OsSTA28-20,
28-23 and 28-28; OsSTA99-7, 99-23 and 99-30; OsSTA208-2, 208-4 and 208-16) with reduced expression of OsSTA (2-8 fold) were selected for further analysis. The expression levels of OsSTA genes in these RNAi $\mathrm{T}_{2}$ plants were stably repressed (Figure 9 and Additional file 5: Figure S4). The defects of pollen and anther in OsSTA RNAi T 2 plants were observed (Figure 9). Statistical analyses of pollen fertility and germination data in OsSTA RNAi and wild-type (WT) ZH11 plants were shown in Table 1.

In OsSTA28 RNAi rice plants, the anther and pollen developed normally from hypodermal archesporial cells to early bi-cellular pollen, but iodine staining of mature pollen showed that more than half were sterile (Figure 9D). In addition, cross sections of mature anthers of OsSTA28 RNAi plants revealed that sterile pollend were shrunken 


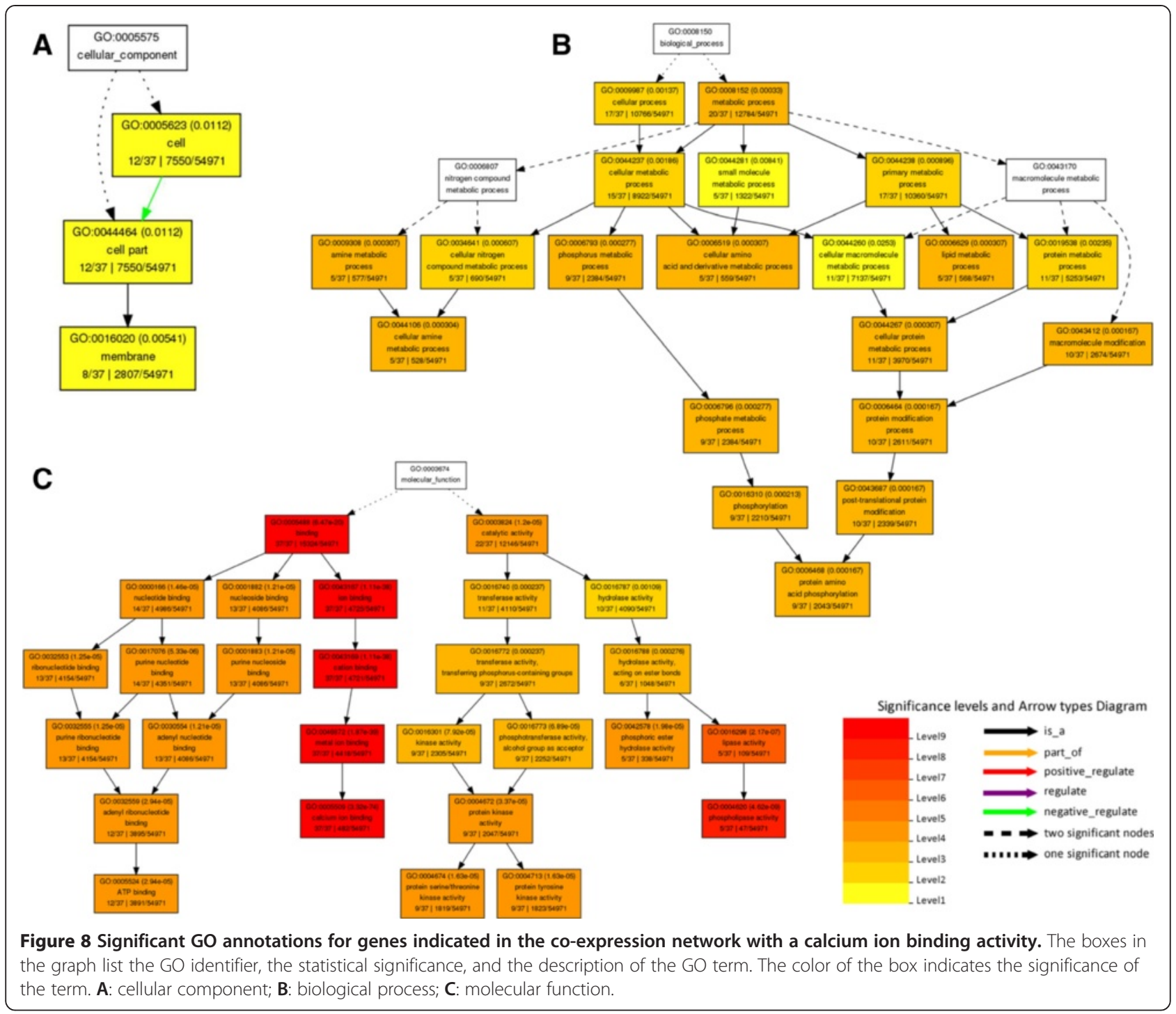

and undyed compared to fertile pollens (Figure 9E). In situ hybridization showed that OsSTA28 was expressed in tricellular pollen and anther walls after microspores underwent first mitosis. Protein conserved domain analysis showed that OsSTA28 contained RRC1, FYVE, and BRX domains. The previous study revealed that $F A B 1 A$ and $F A B 1 B$ encoded proteins with the FYVE domain and played key roles metabolic processes from bi-cellular to tri-cellular pollen transition in Arabidopsis [24]. According to these results, we speculated that OsSTA28 might be a regulator of pollen fertility by influencing the unknown metabolic materials in rice.

Compared with WT anthers, anthers from OsSTA208 RNAi plants were relatively white, their pollens were only $5-8 \%$ fertile (Table 1 ). Most of the pollens were no dye based on iodine stained mature pollen, and also these pollen grains failed to germinate (Figure 9D). Histological section also showed that the pollens of
OsSTA208 RNAi plants were empty and shrunken inside the mature anther (Figure 9E). It was surprising that OsSTA208 was only expressed in the anther wall instead of pollen from microspore stage to mature anther stage by in situ hybridization detection. Therefore, we speculated that down-regulating expression of OSSTA208 in anther wall might interrupt cross-talks between pollen and anther wall, which could be critical for pollen fertility. Conserved domain analysis showed that OsSTA208 possessed DYW_deaminase, four repeats of PPR, and two DAGK (diacylglycerol kinase) domains. Using the RNAi method, the rice DAGK family was previously found to function in regulating abiotic and biotic stresses through different signaling pathways [25]. Thus, it was possible that OsSTA208 participated in stress response in the anther wall for regulating pollen fertility.

Different from OsSTA28 and OsSTA208, the anther and pollen of OsSTA99 RNAi plants appeared to show a 


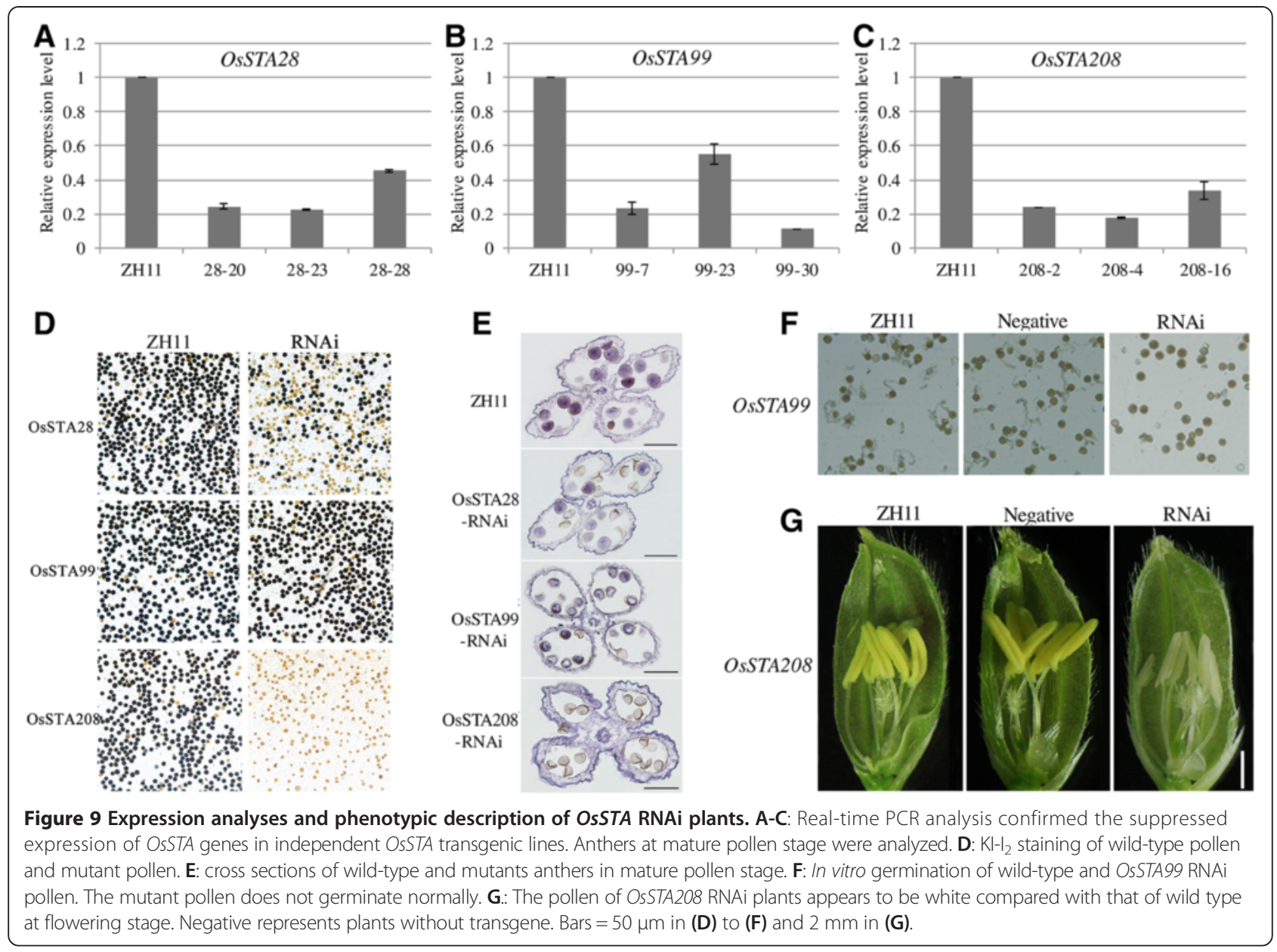

WT phenotype, and the pollen fertility of RNAi plants was almost identical to WT based on statistical analysis of iodine stained mature pollen (Table 1). However, most pollen grains of transgenic plants failed to germinate in vitro under the same culture condition (Figure 9F). OsSTA99 was preferentially expressed in mature anthers and the in situ hybridization showed that OsSTA99 was expressed in tri-cellular pollen and anther walls. Protein conserved domain analysis showed that OsSTA99 possessed only an Apt1 domain. Several prior reports concerning Apt1 and its homologs (SABRE and KIP) revealed that these proteins were involved in membrane trafficking and were required for the high secretory demands of tip growth in pollen tubes or roots [26,27]. It is thus reasonable to suggest that OsSTA99 may function in regulating pollen germination and pollen tube growth by mediating material transportation or signal transferring. In previous studies, $\mathrm{Ca}^{2+}$ and pectinesterase were shown to be involved in pollen grain germination and pollen tube elongation. Thus 8 pectinesterase genes and 8 calcium ion binding genes were selected from the coexpression network to detect their expression levels in OsSTA99 RNAi plants (primers details see Additional file 4: Table S4b). The expression levels of most pectinesterase genes were changed in RNAi plants compared with the WT. Among them, Os11g45730 showed increased expression, whereas the other 6 genes showed decreased expression (Figure 10). While the 6 tested genes with calcium ion binding activity showed decreased expression, the other 2 genes did not change

Table 1 The pollen fertility and pollen germination rate statistics of OsSTA genes RNAi T 2 plants

\begin{tabular}{|c|c|c|c|c|c|c|c|c|c|c|}
\hline \multirow{2}{*}{$\begin{array}{l}\text { Gene } \\
\text { Line }\end{array}$} & \multirow[b]{2}{*}{$\mathrm{ZH} 11$} & \multicolumn{3}{|l|}{ OsSTA28 } & \multicolumn{3}{|l|}{ OsSTA99 } & \multicolumn{3}{|c|}{ OsSTA208 } \\
\hline & & $28-20$ & $28-23$ & $28-28$ & $99-7$ & $99-23$ & $99-30$ & 208-2 & $208-4$ & 208-16 \\
\hline Fertility\% & $84.5 \pm 6.5$ & $31 \pm 13.7^{* *}$ & $32 \pm 12.5^{* *}$ & $38 \pm 16.2^{* *}$ & $78.5 \pm 7.4$ & $80.5 \pm 10.8$ & $74 \pm 9.7^{*}$ & $7 \pm 3.2^{* *}$ & $8 \pm 7.5^{* *}$ & $5 \pm 4.4^{* *}$ \\
\hline Germination\% & $81 \pm 5.8$ & / & / & / & $33 \pm 2.5^{* *}$ & $32 \pm 4.8^{* *}$ & $38.5 \pm 6.3^{* *}$ & / & / & / \\
\hline
\end{tabular}

"I" indicated the experiment not done in the lines. ${ }^{*} \mathrm{t}$ test, with $\mathrm{P}<0.05 ;{ }^{* *} \mathrm{t}$ test, with $\mathrm{P}<0.01$. 


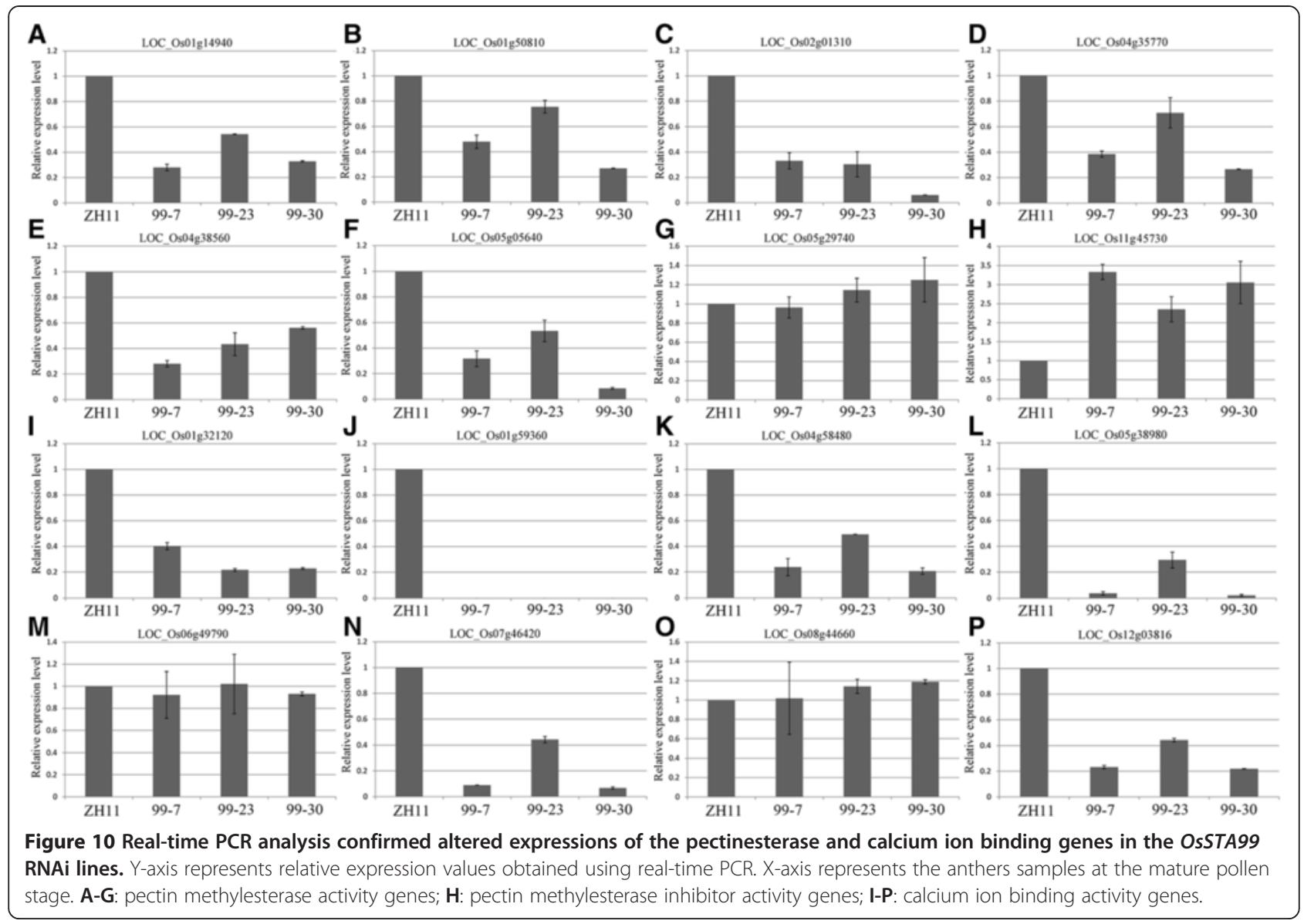

their expression levels. It was inferred that OsSTA99 controlled pollen germination and pollen tube growth by regulating the expression of $\mathrm{Ca}^{2+}$ and pectinesterase relative genes in rice.

Taken together, based on the OSSTA gene expression and observed phenotypes of OsSTA RNAi lines, we concluded that OSSTA genes likely functions to ensure pollen grain germination or pollen tube growth.

\section{Discussion}

\section{OsSTA genes could be essential for rice male fertility by} mediating pollen metabolism

At mature anther stage, the pollen grain maturation was accompanied with the accumulation of starch, lipid and secondary metabolites. These metabolic activities are important for male gametophyte fertility. Here, the GO annotations analysis of 291 OsSTA genes revealed that the largest group consisting of 70 genes had "enzymatic activity", and 67 genes took part in "metabolic process". It was notable that 16 OsSTA genes belonged to the "kinase-like genes". In the past decades, plant kinases were found to be vital for pollen fertility. VPS34 encoded a phosphatidylinositol 3-kinase in Arabidopsis, and vps34 mutants showed male gametophyte abnormality with large vacuoles and no nuclear in pollen grains in the mature pollen stage, indicating VPS34 was essential for pollen maturation [28]. Moreover, the metabolic activities of mature pollen influenced pollen grain germination. For example, Alpha-Glucan water dikinase (GWD) was a key enzyme in tomato that controlled the phosphate content of starch and the starch degradation. In gwd mutants, the pollens showed excess starch accumulation and soluble sugars reducing phenotypes, leading to a reduction in pollen germination, which indicated the key role of starch metabolism for pollen germination [29].

In this study, the gene knockdown experiment was performed to determine the function of OsSTA genes in male fertility. We have found that pollen viability was reduced in OsSTA28 and OsSTA208 RNAi plants and their pollens showed varying degrees of debility. It was reported that OsNek3 (OsSTA192) was preferentially expressed in mature anthers and functioned in male fertility of rice [30]. The knockout mutant of OsNek3 did not show obvious pollen-defective phenotype. However, the over-expression of OsNek3 caused a peculiar pollen structure; the outer cell wall of pollen grains fused together. Meanwhile, OsPDC3 (OsSTA202) was a mature pollen-specific gene and encoded a pyruvate decarboxylase that may be 
required in pollen energy metabolism. Over-expression of OSPDC3 caused increased enzyme activity in rice [31]. Here, the conserved domains and GO annotations analysis showed that OsSTA192 (OsNek3) and OsSTA202 (OsPDC3) had the kinase activity, and OsSTA28, OsPDC3 and OsNek3 were included in metabolic process genes group. Therefore, among the OsSTA genes, the kinases and metabolism related genes might play key roles in pollen fertility. It will be essential to further dissect their functions and learn their regulatory relations in the network of anther maturation in rice.

\section{OsSTA genes might regulate pollen germination and pollen tube growth by interaction with $\mathrm{Ca}^{2+}$ or pectinesterase}

In this study, the identification of OsSTA co-expressed genes showed that 31 genes with "pectinesterase activity" and 37 genes with "calcium ion binding activity" were highly expressed in the mature anther. These genes annotated with the pectinesterase activity were regarded as functional factors during pollen tube growth in previous reports [32-35]. The pectin esterification played an important role in determining the mechanical properties of the pollen tube cell wall during tube elongation [32]. The degree of pectin esterification in different pollen tube location was controlled by competitive effect of pectin methylesterase (PME) and pectin methylesterase inhibitor (PMEI) [33,35]. It was reported that the interactions between PMEs and PMEIs regulated the properties and distributions of pectin [34]. The activity of PMEs was inhibited in the presence of PMEIs at the apical region of pollen tube, while the activity of PMEs in the sub-apical region of pollen tube depended on both exocytosis and endocytosis [34]. Pectinesterase genes were highly expressed in mature anther, whereas they changed expression patterns in OsSTA99 RNAi plants. Detailed analysis found that 6 down-regulated genes were defined as $P M E$ based on other reports, while the up-regulated gene was PMEI [34]. On the basis of the results, we hypothesized that the OsSTA99 might be located in the pectinesterase regulatory network for pollen tube growth, and coordinate the expression of PMEs and PMEIs in different pollen tube growth stage.

In our study, the genes encoding calcium ion binding activity proteins were highly expressed in mature anther, and recently, the mechanisms and functions of calcium in pollen tube growth have been extensively reviewed [36]. The tip-focused calcium gradient, calcium oscillation, $\mathrm{Ca}^{2+}$ sensing and flowing are essential for pollen grains germination and tube growth [36]. In Arabidopsis, a calcium-dependent protein kinase CPK32 interacts with calcium channel CNGC18 and activates it to regulate the pollen tube growth [37]. The proteins phosphatase 1 and $2 \mathrm{~A}$ are involved in the regulation of $\mathrm{Ca}^{2+}$ uptake across the plasma membrane in exocytotic activities and in the biosynthesis of cell wall components that control pollen tube development in Picea wilsonii [22]. The CBL1 and $C B L 9$ encode calcineurin B-like (CBL) proteins, which act as $\mathrm{Ca}^{2+}$ sensor to regulate pollen germination and tube growth in Arabidopsis [38]. In OSSTA99 RNAi plants, most of the "calcium ion binding activity" genes showed down-regulated expression, prompting us to suppose that OsSTA99 may be related to $\mathrm{Ca}^{2+}$ regulating pathway in pollen tube growth. It is useful to further clarify how OsSTA99 regulates PMEs and calcium ion related gene expression and elucidates the mechanism of pollen tube elongation.

The gene expression patterns in co-expression network implied that the OSSTA genes might be involved in $\mathrm{Ca}^{2+}$ or pectinesterase regulating pathway during the pollen germination or pollen tube growth. It would provide the clues to find new regulatory genes and explain the molecular mechanisms of pollen germination and pollen tube growth.

\section{OsSTA genes might function in anther dehiscence in response to phytohormones}

It is well known that the anther dehiscence is the final and necessary step for anther development, resulting in the release of pollen grains to pollination, fertilization, and seed set. Recently, studies on a certain number of dehiscent mutants have shown that phytohormones contributed to the control of anther dehiscence. In the tir1 $a f b 1 a f b 2$ afb3 quadruple auxin receptor mutants of Arabidopsis, anther dehiscent was defective as the endothecial lignification occurred prematurely before tapetum degeneration [39]. The DAD1 gene in Arabidopsis encodes a lipase-like protein that catalyzes the production of free LA from cellular lipids as the first step in jasmonic acid biosynthesis. The stomium of anther in $\mathrm{dad} 1$ mutant fails to open and the elongation of the filament is delayed, while the defects are rescued by the exogenous application of jasmonic acid or linolenic acid [40]. HvGAMYB is a transcription factor that first identified in barley aleurone cells. It is upregulated by gibberellin, and the anthers of transgenic plants overexpressing $H \nu G A M Y B$ are male sterile due to a failure in dehiscence with the stomium remaining intact [41]. The previous reports indicated that genes responding to auxin, gibberellins and jasmonic acid were involved in anther dehiscence.

Here, the identification of cis-elements in OSSTA promoters showed that a majority of OsSTA genes could respond to phytohormones. Coincidently, the detailed analysis indicated that the promoters of the largest group consisting of 192 genes had jasmonic acid responsive elements, meanwhile, 138 genes had the auxin response factor, 141 genes could respond to gibberellin. Thus, it appears that the OsSTA genes could regulate 
anther dehiscence by involving phytohormone regulatory network during anther dehiscence.

During anther dehiscence process, anther walls are indispensable for successful pollen grain release. Recently, a mathematical model describing the biomechanics of anther opening incorporates the bilayer structure of the mature anther wall, which comprises the epidermis and the endothecium. The model describes and demonstrates how epidermal dehydration in association with the thickened endothecium to drive anther opening and pollen release [42]. Also, there have been some reports of dehiscence mutants resulting from defects of secondary wall thickening and epidermis change [43-45]. In the Arabidopsis myb26 mutant, the endothecium fails to expand and secondary thickening, which is seen in the WT anther endothecium, fails to occur. Overexpression of MYB26 results in ectopic secondary thickening in the epidermis $[43,45]$. In our study, the in situ hybridization showed that 5 tested OsSTA genes were expressed in the anther wall after the meiosis or first mitosis, which is the time of secondary thickening in the endothecium [43]. Meanwhile, these OsSTA genes had no expression signal in the stomium. This tissue was derived from the differentiation of epidermal cells, which did not undergo secondary thickening. Moreover, promoter analysis of these 5 OsSTA genes showed that they had auxin, gibberellins and jasmonic acid responsive elements. Therefore, we hypothesized that some OsSTA genes might be involved in anther wall development and anther dehiscence through their roles in phytohormone regulation.

\section{Conclusion}

In conclusion, microarray expression profiling was used to investigate the mature anther preferentially expressed genes in rice. Using GO enrichment analysis and cis-elements identification in OsSTA gene promoters we showed that the OsSTA genes may involve in the anther maturation through different processes, such as pollen germination regulation and pollen tube growth by interaction with $\mathrm{Ca}^{2+}$ or pectinesterase, or participated in anther dehiscence through response for phytohormones. The gene knockdown experiment showed the male sterility and defect of pollen germination in OSSTA RNAi transgenic plants when the gene expression level reduced. All of the researches will provide the basis for understanding the mechanism of OsSTA genes in rice anther growth. The findings in our work would be useful in selecting candidate genes for functional research of OsSTA members during the anther maturation in rice.

\section{Methods}

OsSTA genes identification and chromosomal localization The tissue-specific expressed gene data was used to identify the mature anther-preferentially expressed genes in the entire life cycle of rice, and the specifically expressed genes in mature anther were selected for analysis [15]. By eliminating the unannotated genes in Rice Genome Annotation Project database, the remaining ones were considered as mature anther-preferentially expressed genes. Detail information of the OSSTA genes was procured from MSU, KOME and Pfam database, including accession number, Pfam domain, chromosomal location, ORF length, introns number and protein parameters.

Each of the OSSTA genes was mapped on rice chromosomes according to their positions available in Rice Genome Annotation Project database. The distribution of OsSTA genes was drawn by MapInspect (http://www. plantbreeding.wur.nl/UK/software_mapinspect.html).

\section{Expression analysis of OSSTA genes in rice}

Expression profiles of OsSTA genes in rice 21 tissues and anthers at 8 anther developmental stages for MH63 and Nipponbare were extracted from GSE19024 and GSE13988 Affymetrix rice microarray in NCBI database [7,15]. The gene average expression level of biological replicates for each sample was used for analysis. Expression values of each gene were logarithmed in Microsoft excel, and cluster analyses were performed using J-express 2011 with euclidean distances and hierarchical cluster method of "complete linkage". When more than one probe set was available for one gene, the higher signal value of the probe sets was used for analysis.

\section{Identification of correlated genes and GO analyses}

First, we computed the PCCs for all pairwise relationships between the 112 OsSTA genes in two sets of transcriptomes comprising a total of 190 microarray experiments by $\mathrm{R}-2.14 .1$ project. Then, the co-expression data were downloaded from the CREP database with PCCs greater than 0.8. By getting all the correlated genes together and eliminating the repeat genes, 1282 genes were used for the $\mathrm{GO}$ analysis.

GO enrichment was performed by Singular Enrichment Analysis (SEA) tool in agriGO database (http://bioinfo. cau.edu.cn/agriGO/analysis.php) with default parameters using the rice MSU6.1 genome annotation as background. Statistical significance was determined using Fisher's exact test and Yekutieli multi-test adjustment.

\section{Quantitative real-time PCR}

The cDNAs were amplified with gene-specific primers using Primer5 software. An ubiquitin gene, which showed constant expression in every sample, was chosen as an internal control for data normalization. Total RNA was isolated using RNAiso (Takara) and treated with RNase-free DNaseI (Takara) for 30 min to eliminate possible contaminating DNA. First strand cDNA was 
synthesized from total RNA with an oligo(dT)18 primer in a $20 \mu \mathrm{l}$ reaction (diluted to $40 \mu \mathrm{l}$ before use) using an M-MLV Reverse Transcriptase (Promega) according to the manufacturer's instructions.

Real-time PCR was performed in a $10 \mu \mathrm{l}$ volume containing $5 \mu \mathrm{l} 2 \times$ SYBR $^{\circ}$ Premix Ex Taq ${ }^{\mathrm{Tm}}$ (TaKaRa), $0.5 \mu \mathrm{l}$ of Rox Reference Dye II (Takara), $1 \mu \mathrm{l}$ of the cDNA sample, $2 \mu \mathrm{M}$ of each gene-specific primer. The PCR conditions were as follows: $95^{\circ} \mathrm{C}$ for 3 min, 40 cycles of $95^{\circ} \mathrm{C}$ for $5 \mathrm{~s}$, $60{ }^{\circ} \mathrm{C}$ for $34 \mathrm{~s}$. Three replicates were used for each sample. Reaction was conducted on ABI StepOne "meal-time PCR instrument (Applied Biosystems). We analyzed the relative transcript abundance using 2- $\Delta \Delta C$ T method, and the tissue with the highest expression signal except stamen was regarded as 1 .

\section{In situ hybridization}

Materials for in situ hybridization were sampled and immediately fixed in RNase-free FAA solution (4\% formaldehyde, $10 \%$ acetic acid, $50 \%$ ethanol). The materials of roots, stems and flag leaves in flowering stage, anthers from pollen mother cell stage to tri-cellular pollen stage were used for analysis [16]. For the probe synthesis, the fragments used for in situ hybridization were amplified using the same primers with real-time PCR and subcloned into pGEM-T vector. Dig oxigenin-labeled RNA probes were prepared using a DIG Northern Starter Kit (Roche). T7 and SP6 RNA polymerase were used to generate the sense and antisense RNA probes by in vitro transcription according to the manufacturer's instructions. The in situ hybridization experiment was performed as described in the Cold Spring Harbor Arabidopsis Molecular Genetics Course (www.Arabidopsis.org/cshl-course/5in_situ.html). The hybridization signals were observed and photographed under Olympus BX53 microscope using SPOT color camera. All photos were treated with Adobe Photoshop CS5 software.

\section{In vitro pollen germination and pollen $\mathrm{KI}^{-} \mathrm{I}_{2}$ staining}

Pollen grains from dehisced anthers (WT and RNAi plants) were placed on grass slides at $35{ }^{\circ} \mathrm{C}$ for $2 \mathrm{~h}$ in a pollen germination medium consisting of $1 \mathrm{mM} \mathrm{CaCl}$, $1 \mathrm{mM} \mathrm{KCl}, 0.8 \mathrm{mM} \mathrm{MgSO}, 1.6 \mathrm{mM} \mathrm{H}_{3} \mathrm{BO}_{3}, 30 \mathrm{mM}$ $\mathrm{CaSO}_{4}, 0.03 \%$ casein, $0.3 \%$ 2-(N-morpholino) ethanesulfonic acid, $10 \%$ sucrose and $12.5 \%$ polyethylene glycol. The humidity was maintained at above $90 \%$. The $1 \%$ iodium potassium-iodide solution was used for pollen fertility staining. The germination pollen grains and $\mathrm{KI}-\mathrm{I}_{2}$ stained pollens were observed with a microscope (Olympus, BX53) in bright-field illumination. Five fields per slide were photographed for statistics. In order to get accurate data, 20 plants from every RNAi line were selected for the experiments, and three anthers from panicle top, middle part and basal were used for analysis. The EXCEL 2010 was performed for the statistical and significance analysis.

\section{Plant materials and growth condition}

All plants were grown under long-day conditions under natural light in Wuhan, China. ZH11 was planted as WT in this study. The dsRNA was carried out according to the method [21]. A portion of coding sequence fragment was amplified using primer set from OsSTA28, OsSTA99 and OsSTA208 cDNA clone and cloned into pMD18-T vector (Takara). The amplified fragment in the T-vector was transferred to final pDS1301 vector with KpnI/BamHI and SacI/SpeI. The final OsSTA-RNAi construct was transformed to Agrobacterium strain EH105A. Rice transformation was performed in the ZH11 callus, screened by hygromycin and transgenic plants were regenerated. The mature anthers before flowering were chose for gene suppressed expression verification.

\section{Cytology observation of anther development}

The anther from sporogenous cell stage, pollen mother cell stage, meiosis stage, microspore stage, vacuolated pollen stage, bi-cellular pollen stage, and mature pollen stage were chosen for the cytological observations to identify defects in anther development. Ten plants of each RNAi line and 5 anthers per plant were paraffin sectioned for analysis. Paraffin sections were made according to the method described in a previous article [46]. The phenotypes were observed and photographed under Olympus BX53 microscope using SPOT color camera.

\section{Additional files}

Additional file 1: Table S1. The Affymetrix microarray data of OSSTA genes in various tissues during rice life cycle and rice male reproductive process.

Additional file 2: Table S2. Detailed information of samples used in the microarray analysis.

Additional file 3: Table S3. Detailed information of genomic sequences and protein characteristics about 291 OsSTA genes.

Additional file 4: Table S4. SSTA real-time PCR confirmed primers.

Additional file 5: Figure S1. In situ localization of OSSTA transcripts in vegetative organs in ZH11. A7-A9: OsSTA28; B7-B9: OsSTA208; C7-C9: OsSTA196; D7-D9: OsSTA99; E7-E9: OsSTA68; A7-E7: root; A8-E8: stem; A9-E9: leaf. Bars $=50 \mu \mathrm{m}$. Figure S2. Significant GO annotations for genes indicated in the co-expression networks with OsSTAs. The boxes in the graph list the GO identifier, the statistical significance, and the description of the GO term. The color of the box indicates the significance of the term $(p<0.05)$. A: biological process; B: molecular function; C: cellular component. Figure S3. Suppressed OSSTA gene expression in mature anther of $T_{0}$ RNAi plants. Y-axis represents relative expression values obtained using real-time PCR. X-axis represents the independent transgenic plants. Figure S4. Suppressed OSSTA genes expression in mature panicles and pollen fertility of $\mathrm{T}_{2}$ RNAi plants. $\mathrm{X}$-axis represents the independent transgenic plants. 
Additional file 6: Table S5. GO annotations for genes indicated in the agriGO database. FDR indicates false discovery rate. P: biological process; C: cellular component; F: molecular function.

Additional file 7: Table S6. The distribution of Pearson's correlation coefficients (PCC) from 291 OsSTA genes and detailed information of the 1510 co-expressed genes.

Additional file 8: Table S7. Detailed information of cis-elements in the OSSTA promoters and cis-elements for phytohormone responses.

\section{Abbreviations}

GO: Gene ontology; RNAi: RNA interference; WT: Wild type; MH63: Minghui63; ZS97: Zhenshan97; ZH11: Zhonghua11; PCC: Pearson's correlation coefficients; PME: Pectin methylesterase; PMEl: Pectin methylesterase inhibitor.

\section{Competing interests}

The authors declare that they have no competing interests.

\section{Authors' contributions}

$J Y$ conceived and designed the research. SL, ZL and YO collected and analyzed the data. SL, CC, YW and XS performed the experiments and statistical analysis. SL and JY wrote the paper. All authors read and approved the final manuscript.

\section{Acknowledgments}

We would like to thank Prof. Zhongchi Liu for her critical reading of manuscript and language editing. We thank Prof. Chungen Hu for helpful advice in this study. This research was supported by grants from the National Natural Science Foundation of China (Project J1103510 and 30971551).

\section{Author details}

'College of Life Science and Technology, Huazhong Agricultural University, Wuhan 430070, China. ${ }^{2}$ College of Plant Science and technology, Huazhong Agricultural University, Wuhan 430070, China. ${ }^{3}$ National Key Laboratory of Crop Genetic Improvement and National Center of Plant Gene Research (Wuhan), Huazhong Agricultural University, Wuhan 430070, China.

\section{Received: 28 September 2014 Accepted: 30 January 2015}

\section{Published online: 19 February 2015}

\section{References}

1. Itoh J, Nonomura K, Ikeda K, Yamaki S, Inukai Y, Yamagishi H. Rice plant development: from zygote to spikelet. Plant Cell Physiol. 2005;46:23-47.

2. Ma H. Molecular genetic analyses of microsporogenesis and microgametogenesis in flowering plants. Annu Rev Plant Biol. 2005;56:393-434

3. Ouyang Y, Liu YG, Zhang Q. Hybrid sterility in plant: stories from rice. Curr Opin Plant Biol. 2010;13:186-92.

4. Zhang DB, Wilson ZA. Stamen specification and anther development in rice. Chin Sci Bull. 2009:54:2342-53.

5. Hobo T, Suwabe K, Aya K, Suzuki G, Yano K, Ishimizu T, et al. Various spatiotemporal expression profiles of anther-expressed genes in rice. Plant Cell Physiol. 2008;49:1417-28.

6. Suwabe K, Suzuki G, Takahashi H, Shiono K, Endo M, Yano K, et al. Separated transcriptomes of male gametophyte and tapetum in rice: validity of a laser microdissection (LM) microarray. Plant Cell Physiol. 2008:49:1407-16.

7. Fujita M, Horiuchi Y, Ueda Y, Mizuta Y, Kubo T, Yano K, et al. Rice expression atlas in reproductive development. Plant Cell Physiol. 2010;51:2060-81.

8. Deveshwar P, Bovill WD, Sharma R, Able JA, Kapoor S. Analysis of anther transcriptomes to identify genes contributing to meiosis and male gametophyte development in rice. BMC Plant Biol. 2011;11:78.

9. Thangasamy S, Guo CL, Chuang MH, Lai MH, Chen J, Jauh GY. Rice SIZ1, a SUMO E3 ligase, controls spikelet fertility through regulation of anther dehiscence. New Phytol. 2011;189:869-82.

10. Zhou SR, Wang Y, Li WC, Zhao ZG, Ren YL, Gu SH, et al. Pollen Semi-Sterility1 Encodes a Kinesin-1-Like Protein Important for Male Meiosis, Anther Dehiscence, and Fertility in Rice. Plant Cell. 2011:23:111-29.

11. Huang J, Zhao $X$, Cheng $K$, Jiang $Y$, Ouyang $Y, X u$, et al. OsAP65, a rice aspartic protease, is essential for male fertility and plays a role in pollen germination and pollen tube growth. J Exp Bot. 2013;64:3351-60.
12. Jiang $L$, Yang $S L$, Xie LF, Puah $C S$, Zhang $X Q$, Yang WC, et al. VANGUARD1 encodes a pectin methylesterase that enhances pollen tube growth in the Arabidopsis style and transmitting tract. Plant Cell. 2005;17:584-96.

13. Yoon GM, Dowd PE, Gilroy S, McCubbin AG. Calcium-dependent protein kinase isoforms in Petunia have distinct functions in pollen tube growth, including regulating polarity. Plant Cell. 2006;18:867-78.

14. Deng Y, Wang W, Li WQ, Xia C, Liao HZ, Zhang XQ, et al. MALE GAMETOPHYTE DEFECTIVE 2, encoding a sialyltransferase-like protein, is required for normal pollen germination and pollen tube growth in Arabidopsis. J Integr Plant Biol. 2010;52:829-43.

15. Wang L, Xie W, Chen Y, Tang W, Yang J, Ye R, et al. A dynamic gene expression atlas covering the entire life cycle of rice. Plant $J$. 2010;61:752-66.

16. Ikeda K, Sunohara H, Nagato Y. Developmental course of inflorescence and spikelet in rice. Breed Sci. 2004:54:147-56.

17. Du Z, Zhou X, Ling Y, Zhang Z, Su Z. agriGO: a GO analysis toolkit for the agricultural community. Nucleic Acids Res. 2010;38:W64-70.

18. Childs KL, Davidson RM, Buell CR. Gene coexpression network analysis as a source of functional annotation for rice genes. PloS one. 2011;6:e22196.

19. Ouyang Y, Huang X, Lu Z, Yao J. Genomic survey, expression profile and co-expression network analysis of OsWD40 family in rice. BMC genomics. 2012;13:100

20. Hirano K, Aya K, Hobo T, Sakakibara H, Kojima M, Shim RA, et al. Comprehensive transcriptome analysis of phytohormone biosynthesis and signaling genes in microspore/pollen and tapetum of rice. Plant Cell Physiol. 2008:49:1429-50.

21. Dai M, Hu Y, Zhao Y, Liu H, Zhou DX. A WUSCHEL-LIKE HOMEOBOX gene represses a YABBY gene expression required for rice leaf development. Plant physiology. 2007;144:380-90.

22. Kong L, Wang M, Wang $Q$, Wang $X$, Lin J. Protein phosphatases 1 and $2 A$ and the regulation of calcium uptake and pollen tube development in Picea wilsonii. Tree physiology. 2006;26:1001-12.

23. Zhai Z, Sooksa-nguan T, Vatamaniuk OK. Establishing RNA interference as a reverse-genetic approach for gene functional analysis in protoplasts. Plant physiology. 2009;149:642-52.

24. Whitley P, Hinz S, Doughty J. Arabidopsis FAB1/PIKfyve proteins are essential for development of viable pollen. Plant physiology. 2009;151:1812-22.

25. Ge H, Chen $C$, Jing W, Zhang $Q$, Wang $H$, Wang $R$, et al. The rice diacylglycerol kinase family: functional analysis using transient RNA interference. Front Plant Sci. 2012;3:60

26. Yu H, Luo N, Sun L, Liu D. HPS4/SABRE regulates plant responses to phosphate starvation through antagonistic interaction with ethylene signalling. J Exp Bot. 2012;63:4527-38.

27. $\mathrm{Xu} Z$ Z, Dooner HK. The maize aberrant pollen transmission 1 gene is a SABRE/KIP homolog required for pollen tube growth. Genetics. 2006;172:1251-61.

28. Lee Y, Kim ES, Choi Y, Hwang I, Staiger CJ, Chung YY. The Arabidopsis phosphatidylinositol 3-kinase is important for pollen development. Plant Physiol. 2008;147:1886-97.

29. Nashilevitz S, Melamed-Bessudo C, Aharoni A, Kossmann J, Wolf S, Levy AA The legwd mutant uncovers the role of starch phosphorylation in pollen development and germination in tomato. Plant J. 2009;57:1-13.

30. Fujii S, Yamada M, Toriyama K. Cytoplasmic male sterility-related protein kinase, OsNek3, is regulated downstream of mitochondrial protein phosphatase $2 \mathrm{C}$, DCW11. Plant Cell Physiol. 2009:50:828-37.

31. Bo C, Bin H. Primary Function Analysis of a Pyruvate Decarboxylase Gene, OsPDC3, in Rice. Chinese J Rice Sci. 2011:25:567-74.

32. Chebli Y, Kaneda M, Zerzour R, Geitmann A. The cell wall of the Arabidopsis pollen tube-spatial distribution, recycling, and network formation of polysaccharides. Plant Physiol. 2012;160:1940-55.

33. Zhang GY, Feng J, Wu J, Wang XW. BoPMEl1, a pollen-specific pectin methylesterase inhibitor, has an essential role in pollen tube growth. Planta. 2010;231:1323-34.

34. Rockel N, Wolf S, Kost B, Rausch T, Greiner S. Elaborate spatial patterning of cell-wall PME and PMEl at the pollen tube tip involves PMEl endocytosis, and reflects the distribution of esterified and de-esterified pectins. Plant J. 2008;53:133-43.

35. Bosch M, Cheung AY, Hepler PK. Pectin methylesterase, a regulator of pollen tube growth. Plant Physiol. 2005;138:1334-46.

36. Steinhorst L, Kudla J. Calcium - a central regulator of pollen germination and tube growth. Biochim Biophys Acta. 1833;2013:1573-81. 
37. Zhou L, Lan W, Jiang Y, Fang W, Luan S. A Calcium-Dependent Protein Kinase Interacts with and Activates A Calcium Channel to Regulate Pollen Tube Growth. Mol Plant. 2013;7:369-76.

38. Mahs A, Steinhorst L, Han JP, Shen LK, Wang Y, Kudla J. The calcineurin B-like Ca2+ sensors CBL1 and CBL9 function in pollen germination and pollen tube growth in Arabidopsis. Mol Plant. 2013;6:1149-62.

39. Cecchetti V, Altamura MM, Falasca G, Costantino P, Cardarelli M. Auxin regulates Arabidopsis anther dehiscence, pollen maturation, and filament elongation. Plant Cell. 2008;20:1760-74.

40. Ishiguro S, Kawai-Oda A, Ueda J, Nishida I, Okada K. The DEFECTIVE IN ANTHER DEHISCIENCE gene encodes a novel phospholipase A1 catalyzing the initial step of jasmonic acid biosynthesis, which synchronizes pollen maturation, anther dehiscence, and flower opening in Arabidopsis. Plant Cell. 2001;13:2191-209.

41. Murray F, Kalla R, Jacobsen J, Gubler F. A role for HvGAMYB in anther development. Plant J. 2003;33:481-91.

42. Nelson MR, Band LR, Dyson RJ, Lessinnes T, Wells DM, Yang C, et al. A biomechanical model of anther opening reveals the roles of dehydration and secondary thickening. New Phytol. 2012;196:1030-7.

43. Dawson J, Sözen E, Vizir I, Van Waeyenberge S, Wilson Z, Mulligan B. Characterization and genetic mapping of a mutation (ms35) which prevents anther dehiscence in Arabidopsis thaliana by affecting secondary wall thickening in the endothecium. New Phytol. 1999;144:213-22.

44. Kim YY, Jung KW, Jeung JU, Shin JS. A novel F-box protein represses endothecial secondary wall thickening for anther dehiscence in Arabidopsis thaliana. J Plant Physiol. 2012;169:212-6.

45. Yang C, Xu Z, Song J, Conner K, Vizcay Barrena G, Wilson ZA. Arabidopsis MYB26/MALE STERILE35 regulates secondary thickening in the endothecium and is essential for anther dehiscence. Plant Cell. 2007:19:534-48.

46. Yao JL, Zhou Y, Hu CG. Apomixis in Eulaliopsis binata: characterization of reproductive mode and endosperm development. Sex Plant Reprod. 2007;20:151-8.

\section{Submit your next manuscript to BioMed Central and take full advantage of:}

- Convenient online submission

- Thorough peer review

- No space constraints or color figure charges

- Immediate publication on acceptance

- Inclusion in PubMed, CAS, Scopus and Google Scholar

- Research which is freely available for redistribution 